\title{
Seismic safety of low ductility structures used in Spain
}

\author{
J. C. Vielma • A. H. Barbat · S. Oller
}

Received: 26 August 2008 / Accepted: 10 May 2009 / Published online: 29 May 2009

(C) Springer Science+Business Media B.V. 2009

\begin{abstract}
The most important aspects of the design, seismic damage evaluation and safety assessment of structures with low ductility like waffle slabs buildings or flat beams framed buildings are examined in this work. These reinforced concrete structural typologies are the most used in Spain for new buildings but many seismic codes do not recommend them in seismic areas. Their expected seismic performance and safety are evaluated herein by means of incremental non linear structural analysis (pushover analysis) and incremental dynamic analysis which provides capacity curves allowing evaluating their seismic behavior. The seismic hazard is described by means of the reduced $5 \%$ damped elastic response spectrum of the Spanish seismic design code. The most important results of the study are the fragility curves calculated for the mentioned building types, which allow obtaining the probability of different damage states of the structures as well as damage probability matrices. The results, which show high vulnerability of the studied low ductility building classes, are compared with those corresponding to ductile framed structures.
\end{abstract}

Keywords Ductility - Behavior factor · Overstrength · Pushover analysis · Capacity curve · Damage probability matrices

J. C. Vielma

Decanato de Ingeniería Civil, Departamento de Estructuras, Lisandro Alvarado University, Av. La Salle entre Av. Las industrias y Av. Benítez, Barquisimeto, Venezuela e-mail: jcvielma@ucla.edu.ve

A. H. Barbat $(\varangle) \cdot$ S. Oller

Departamento de Resistencia de Materiales y Estructuras en la Ingeniería, E.T.S. deIngenieros de Caminos Canales y Puertos, Technical University of Catalonia, UPC, Edificio C1,

Campus Norte, Jordi Girona 1-3, 0034 Barcelona, Spain

e-mail: alex.barbat@upc.edu

S. Oller

e-mail: sergio.oller@upc.edu 


\section{Introduction}

Among the building typologies applied in the seismic areas of Spain, the most frequent are nowadays those with flat beams (FBFB) and with waffle slabs (WSB). Earthquake-resistant codes in general, and Spanish code NCSE-02 (2002) in particular, assigns ductility values of two to these buildings and classifies them as low ductility buildings. These values are fixed by the code on the premise that buildings expressly designed to have low ductility have a low capacity of energy dissipation and a non-adequate seismic behavior. The adequacy of the response of a structure to a given seismic threat can be evaluated by using an incremental nonlinear structural analysis providing capacity curves (Erberik and Elnashai 2006), examining especially the structural ductility and the overstrength; low ductility buildings have been not extensively studied yet using this procedure. In the past, capacity and performance-based procedures energy dissipation have been used mostly in the evaluation of the seismic behavior of moment-resisting frames (Mwafi and Elnashai 2002a; Fragiacomo et al. 2006). It has to be also mentioned that, apart from ICBO (1997), ICC (2003), and CEN (2004), no other earthquake-resistant code directly refers to overstrength values, which are very important in the determination of behavior factors (Vielma et al. 2006).

The main objective of this article is to evaluate the ductility, the behavior factor and the overstrength values of buildings with low ductility by means of pushover analysis and incremental dynamic analysis (IDA) in order to study their seismic safety. Roof displacements normalized respecting the total height of the building are used as demand parameter. Displacement values corresponding to the yielding point are obtained by using the idealized bilinear

form of the capacity

are determined, the

ongitudinal and trans

he buildings with low

buildings: one with intermediate ductility,
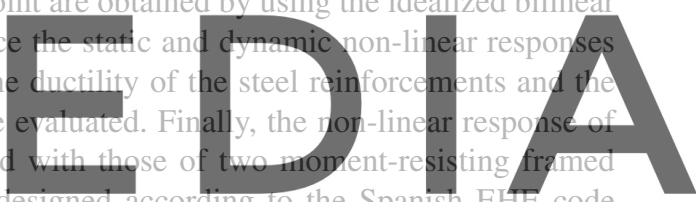

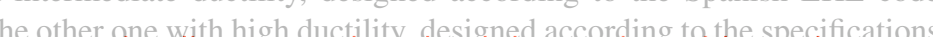

\section{Description of the studied buildings}

To elucidate how structural typology and design influence the global response of buildings structures, four buildings with different characteristics have been studied. The first two buildings, one with waffled slabs, and the other with flat beams, have low ductility and are designed using low behavior factors $(q=2)$. The third is a moment-resisting framed building designed according to the Spanish EHE code for a medium ductility $(q=4)$ and the fourth is a moment-resisting framed building designed according to the Eurocode 2 and the Eurocode 8 , for a high ductility class $(q=5.85)$. All buildings were designed for a PGA of $0.23 \mathrm{~g}$, which is the maximum value prescribed by the NCSE-02 seismic Spanish code.

\subsection{Waffled slabs building}

The waffled slabs building (WSB) has ribs which run along the lines that join the ends of its columns. It has three stories: the first is $4,5 \mathrm{~m}$ high, whereas the other two are $3,0 \mathrm{~m}$ high-a typical configuration for a building whose ground floor is intended for commercial use. It has four spans parallel to the $x$-axis and three spans parallel to the $y$-axis (see Fig. 1a). Figure 1a 


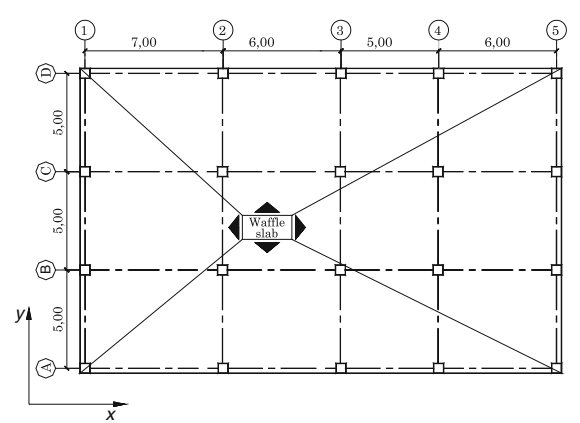

\section{WSB}
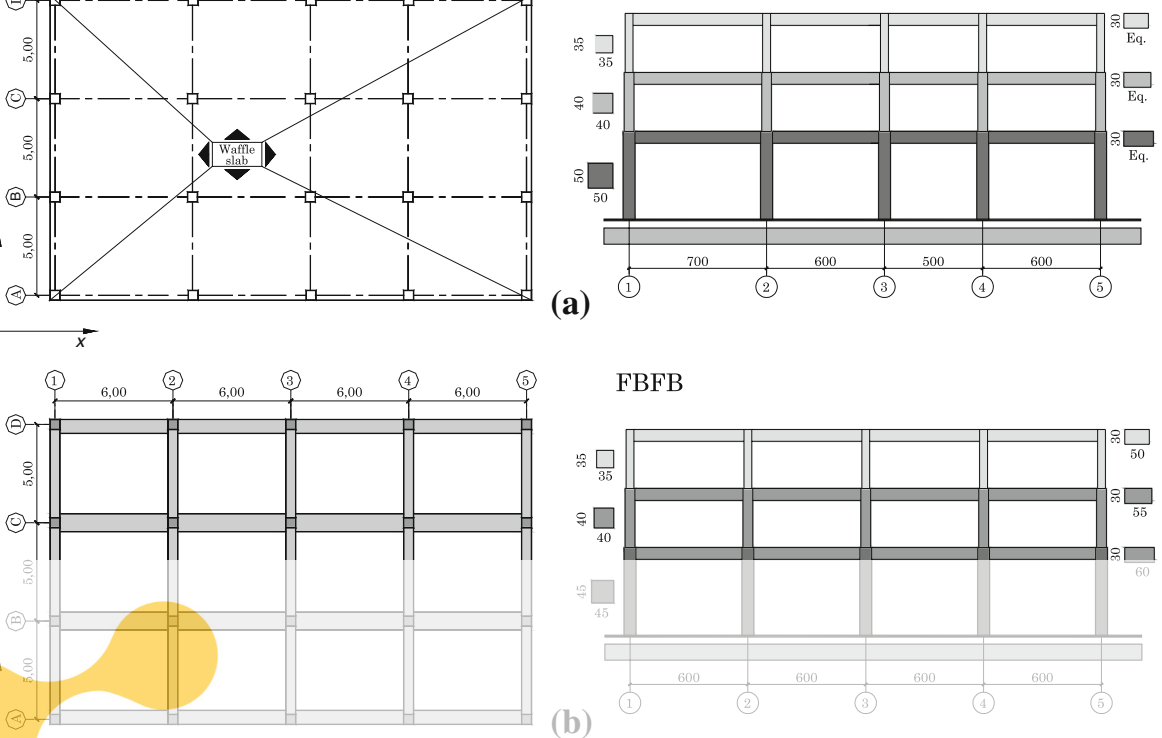

FBFB
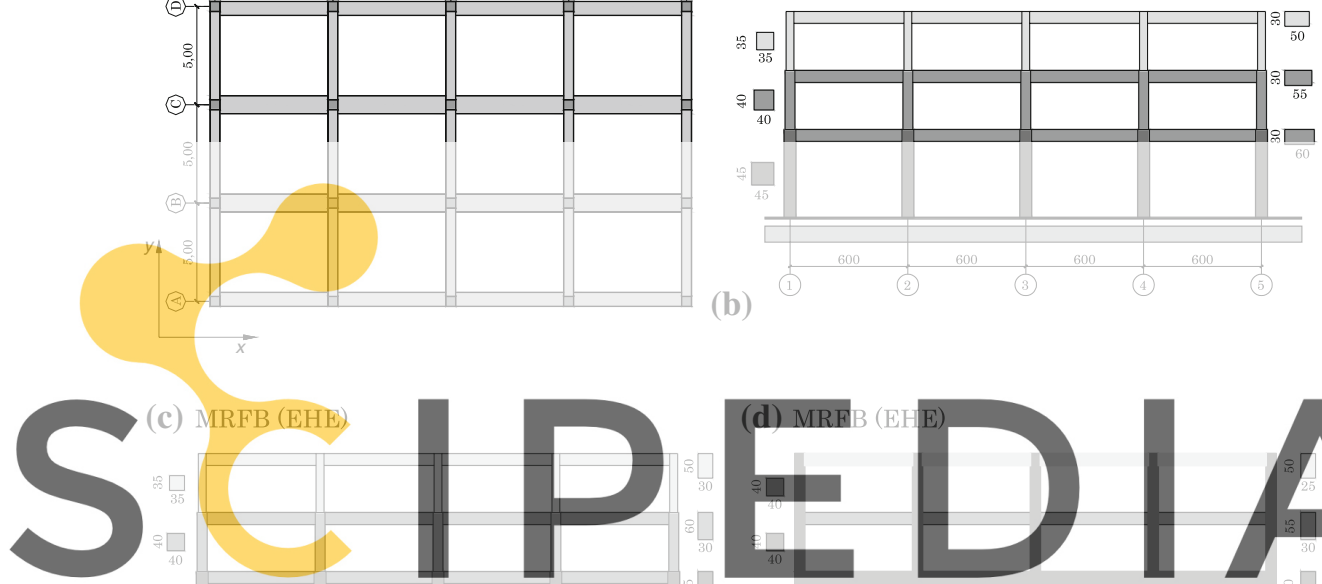

c) MRFB (EHE)
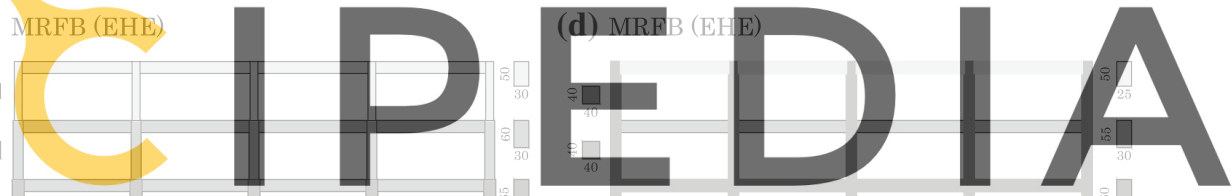

Register for free at https//www.scipedia.com to

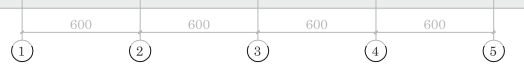

download the version without the watermark

(3)

(5)

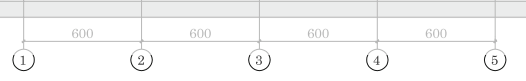

Fig. 1 Typical plan and elevation view of $\mathbf{a}$ the WSB and $\mathbf{b}$ the FBFB (equal at all floors). Typical elevation of $\mathbf{c}$ the MRFB (EHE) and $\mathbf{d}$ of the MRFB (EC)

also shows an equivalent frame from this building; this equivalent frame is obtained by cutting the three dimensional building along lines midway between columns (for this building is $2,50 \mathrm{~m}$ ). The slab has bidirectional ribs, whereby the ribs are orthogonal to each other. The total depth of the slabs is $30 \mathrm{~cm}$. Seismic forces were computed from the stiff soil design spectrum (see Fig. 2).

In the NCSE-02 Spanish code, the behavior factor $q$ is function of the displacement ductility $\mu$ and of the damping ratio $\xi$ of the structure:

$$
q=\frac{\mu}{(5 / \xi)^{0,4}}
$$

The equivalent seismic forces corresponding to all the levels of the buildings were calculated using the modal analysis foreseen in the Spanish seismic code NCSE-02. The inelastic spectrum outlined in the mentioned code has been used, calculated by simply reducing the 


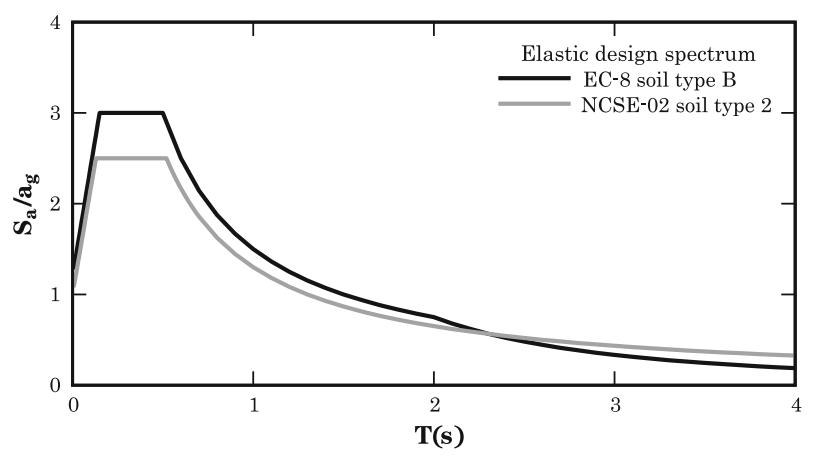

Fig. 2 Elastic design spectra used in the elastic dynamic analysis of the buildings

elastic design spectrum by the behavior factor $q$. The same inelastic spectrum was also used to calculate the seismic forces applied to the WSB.

\subsection{Framed building with flat beams}

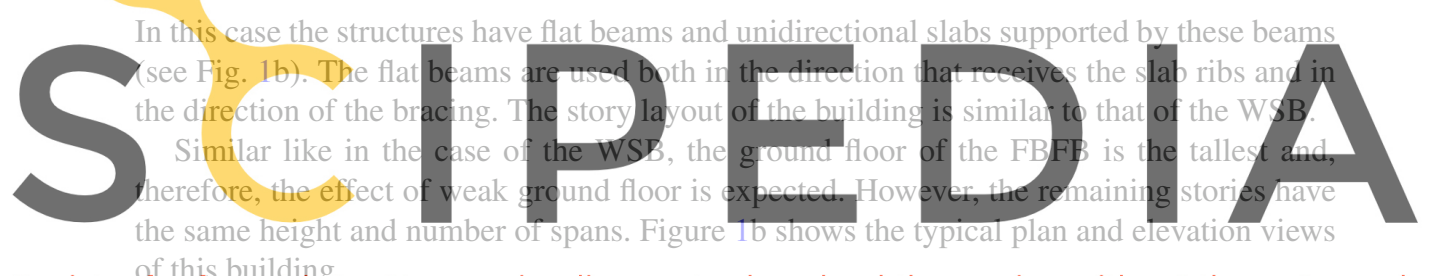

Register for free at https//www.scipedia.com to download the version without the watermark

\subsection{Moment-resisting framed buildings}

Two buildings were designed to study the response of moment-resisting framed buildings: one according to the Spanish EHE and NCSE-02 codes and the second one using Eurocode 2 and Eurocode 8 . Figure 2 shows the spectra used to obtain the seismic forces for both buildings. These buildings are geometrically similar to the FBFB, with one-way ribbed slabs; sections of the elements of the MRFB can be seen in Fig. 1c, d. Seismic design criteria are followed in order to increase the column dimensions, thereby yielding a structure with strong columns and weak beams. Table 1 summarizes the periods of the first nine modes of vibration of the studied buildings.

\section{Non-linear analysis}

The aim of the non-linear analysis performed in this article was to obtain a more realistic response of the buildings designed according to the linear elastic method outlined in the code NCSE-02. This allowed a clear demonstration of how earthquake-resistant design improves structural ductility, while also revealing how non-linear response challenges certain simplifications made during elastic analysis. 
Table 1 Periods of vibration of the four buildings studied

\begin{tabular}{lllll}
\hline Mode & \multicolumn{3}{l}{ Period (s) } \\
\cline { 2 - 5 } & WSFB & FBFB & MRFB (EHE/NCSE-02) & MRFB (EC) \\
\hline 1 & 0.93 & 0.56 & 0.45 & 0.50 \\
2 & 0.91 & 0.50 & 0.44 & 0.48 \\
3 & 0.82 & 0.45 & 0.39 & 0.45 \\
4 & 0.27 & 0.17 & 0.16 & 0.40 \\
5 & 0.26 & 0.15 & 0.16 & 0.36 \\
6 & 0.23 & 0.14 & 0.14 & 0.29 \\
7 & 0.12 & 0.08 & 0.09 & 0.11 \\
8 & 0.11 & 0.07 & 0.09 & 0.10 \\
9 & 0.10 & 0.06 & 0.08 & 0.09 \\
\hline
\end{tabular}

\subsection{Equivalent mechanical models of the buildings}

The non-linear static and dynamic analysis was performed using the PLCd (1991-2009) finite element code. PLCd works with two and three-dimensional solid geometries as well as with prismatic, one-dimensional, members. It provides a solution combining both numerical precision and reasonable computational costs. It deals with kinematics and material nonlinearities and uses visco-elastic, damage volution (Von-Mises, MohrNewmark's method is used to perform the d the used procedure can be found in Barbat et $\mathrm{i}$ ( 2008 ) and
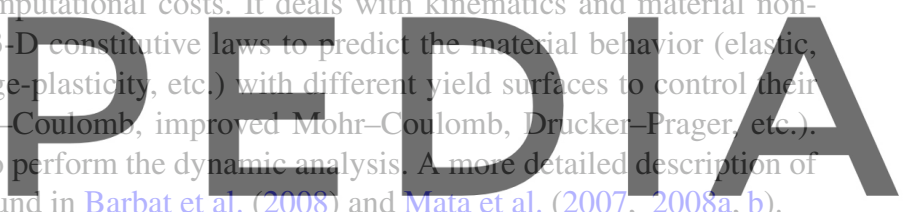

Experimental evidence shows that inelasticity in beam elements can. be formulated in Register for free at https//WwW.scipedia.com to download the version without the watermark by means of concentrated models, sometimes called plastic hinge models, which localize all the inelastic behavior at the ends of the beam by means of ad-hoc force-displacement or moment-curvature relationships. But, in the formulation used in this computer program, the procedure consists of obtaining the constitutive relationship at cross-sectional level by integrating in a selected number of points corresponding to fibers directed along the beam's axis. Thus, the general nonlinear constitutive behavior is included in the geometrically exact nonlinear kinematics formulation for beams proposed by Simo (1985), considering an intermediate curved reference configuration between the straight reference beam and the current configuration. The displacement based method is used for solving the resulting nonlinear problem. Plane cross sections remain plane after the deformation of the structure; therefore, no cross sectional warping is considered, avoiding including additional warping variables in the formulation or iterative procedures to obtain corrected cross sectional strain fields. An appropriated cross sectional analysis is applied for obtaining the cross sectional forces and moments and the consistent tangential tensors in the linearized problem. Thermodynamically consistent constitutive laws are used in describing the material behavior for these beam elements, which allows obtaining a more rational estimation of the energy dissipated by the structures. The simple mixing rule for composition of the materials is also considered in modelling materials for these elements, which are composed by several simple components.

Discretization of frames was performed with finite elements whose lengths vary depending on the column and beam zones with special confinement requirements. These confinement 

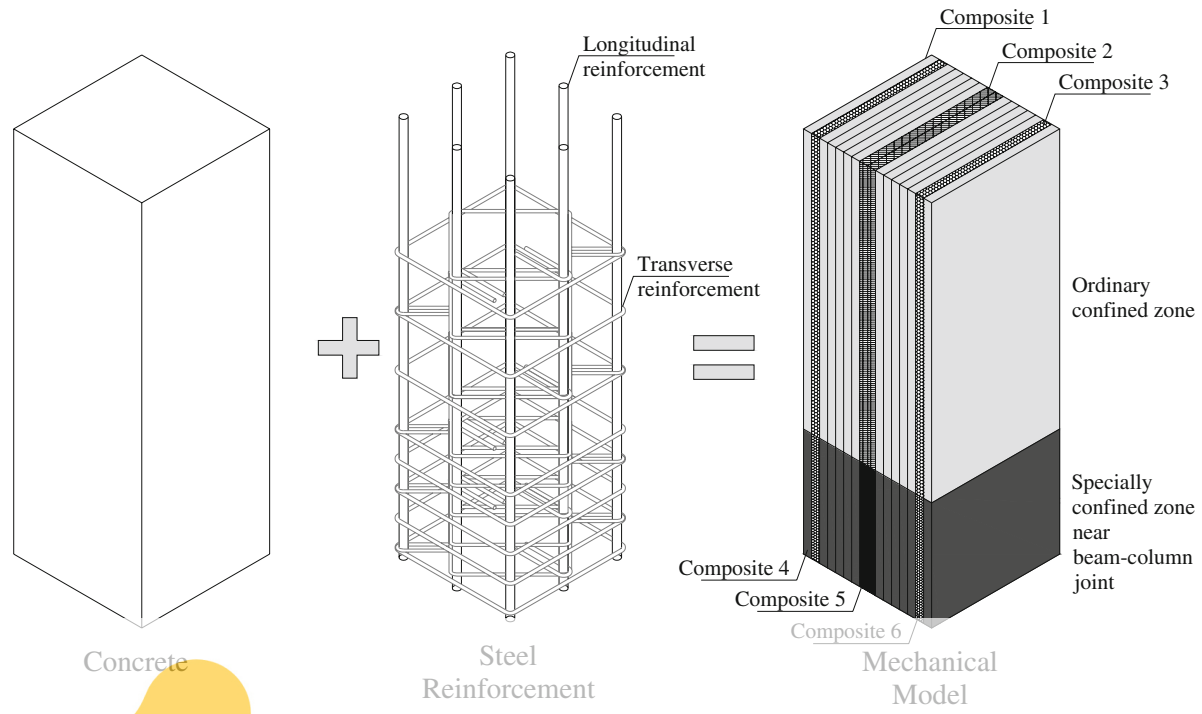

Fig. 3 Discretization of the RC frame's elements

Zones were designed according to the general dimensions of the structural elements, the

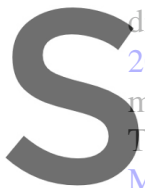

liameters of the long

2009). Frame elemen

materials, characterizec

ransversal reinforce

Mander et al. (1988).
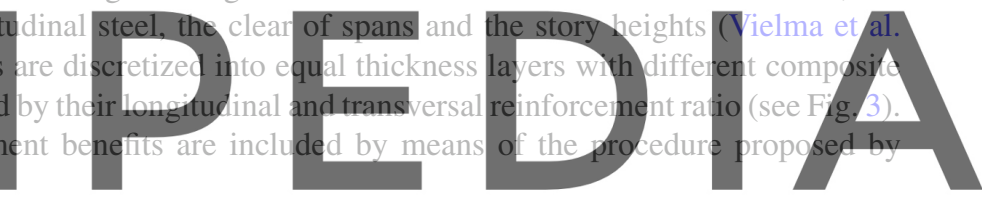

Register for free at https//www.scipedia.com to download the version without the watermark

To evaluate the inelastic response of the four structures, pushover analysis was performed applying a set of lateral forces representing seismic actions corresponding to the first vibration mode. The lateral forces are gradually increased starting with a zero value, passing through the value which induces the transition from elastic to plastic behavior and, ultimately, reaching the value which corresponds to the ultimate drift (i.e., the point at which the structure can no longer support any additional load and collapses). Before the structure is subjected to the lateral loads simulating seismic action, it is first subjected to the action of gravity loads, in agreement with the combinations applied in the elastic analysis. The method applied does not allow for evaluation of torsional effects, being the used model a 2D one.

Although it is difficult to find a method to obtain the global yield and the ultimate displacements (Priestley et al. 2007), a simplified procedure is applied in this work. The non-linear static response obtained via finite element techniques is used to generate the idealized bilinear expression shown in Fig. 2, which has a secant segment from the origin to a point on the capacity curve that corresponds to a $75 \%$ of the maximum base shear (Park 1988). The second segment, which represents the branch of plastic behavior, was obtained by finding the intersection of the aforementioned segment with another, horizontal segment which corresponds to the maximum base shear. The use of this compensation procedure guarantees that the energies dissipated by the ideal system and by the modelled system are equal (see Fig. 4). 


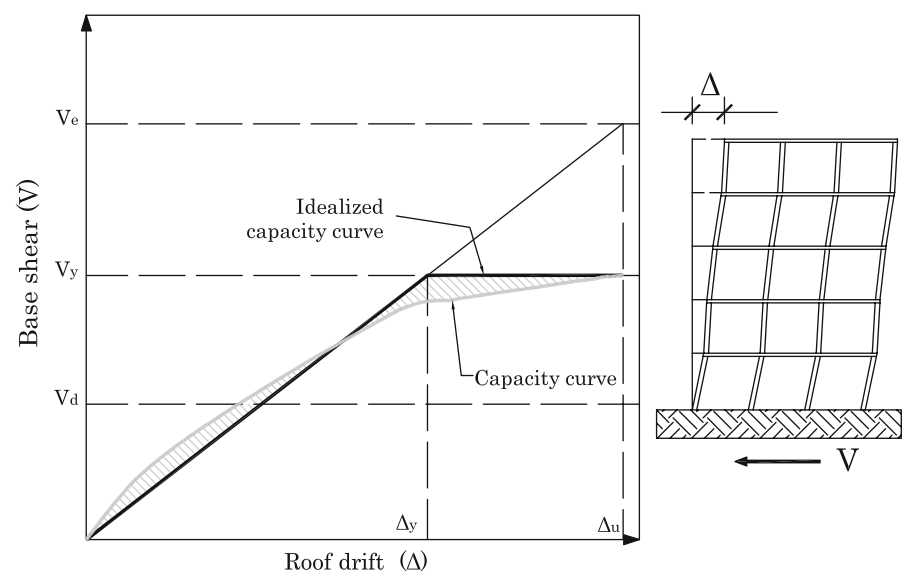

Fig. 4 Scheme for determining the displacement ductility and the overstrength

In a simplified non-linear analysis, there are two variables that characterize the seismic response of buildings. The first one is the displacement ductility $\mu$, defined as

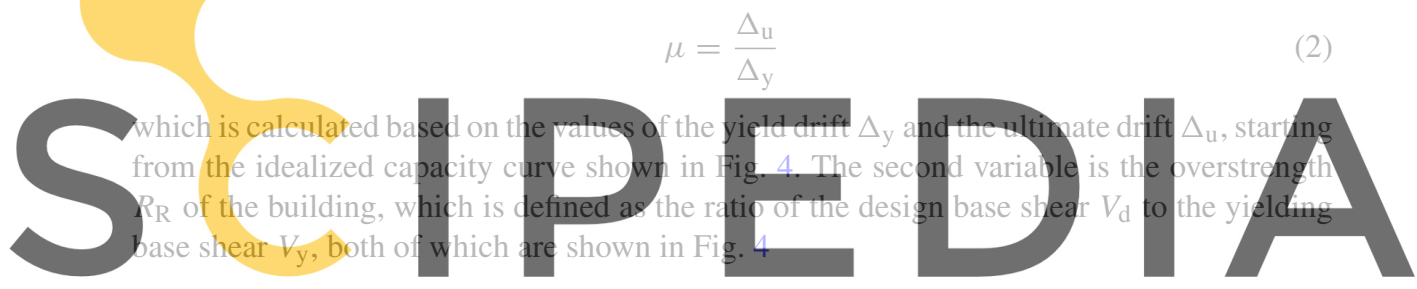
$V_{\mathrm{y}}$

Register for free at https//www.scipedia.com tho $\bar{d}$ download the version without the watermark

The overstrength $R_{\mathrm{R}}$ is like a safety factor applied in design and evaluation of the buildings.

The WSB and FBFB are designed and detailed to have a very low level of ductility as compared with that of the MRFB. The capacity curve is calculated with a mechanical model similar to the equivalent frame method defined in the ACI-318 code (ACI Comitee 318 2005). The analysis is performed by means of the finite element method and using damage and plasticity constitutive models, as well as the Mixing Theory (PLCd 1991-2009; Mata et al. 2007). To control the energy dissipation and ensure the correct behavior of the structure, approximate mean values for strength and for facture energy were used for each constituent material (i.e., steel and concrete) (Car et al. 2000, 2001).

Results of the non linear analysis and the idealized bilinear capacity curve of the WSB are show in Fig. 5. The calculated displacement ductility value of the WSB is 1.57, value which is excessively low, taking into account that the Spanish code NCSE-02 specifies a design value $\mu=2$ for the same structural type. The corresponding overstrength is: $R_{\mathrm{R}}=V_{\mathrm{y}} / V_{\mathrm{d}}=1,92$. The ductility value calculated for this structural class suggests that the ductility factors stipulated in the NCSE-02 earthquake-resistant design code should be revised. Nevertheless, these structures exhibit high overstrength level.

The low ductility response of the WSB can be attributed to the formation of plastic hinges in the transition points between the abacus and the ribs of the waffled slab at the first floor. The elements of the slabs are subject to bending induced by gravitational loads, as well as to the demands to seismic forces; hence, the zones which require special reinforcement are those 


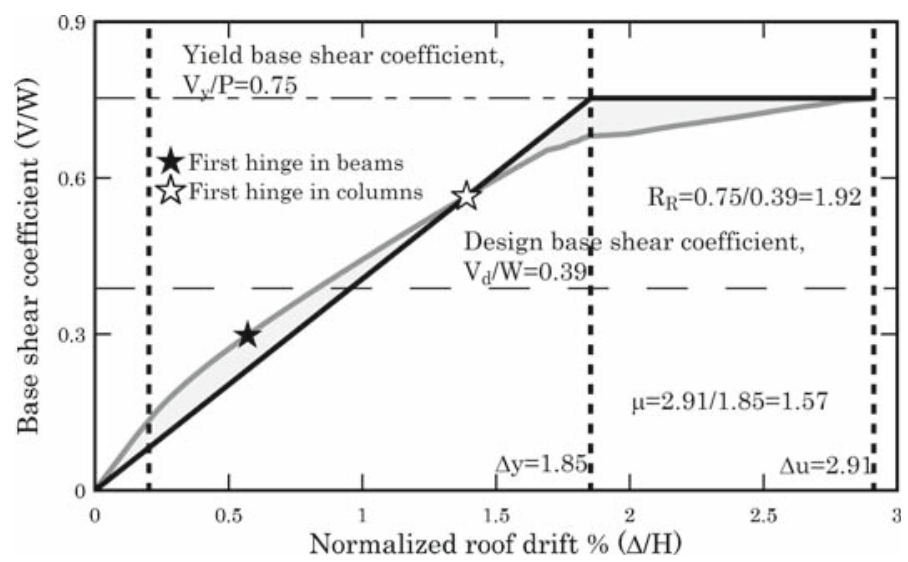

Fig. 5 Idealized bilinear capacity curve WSB

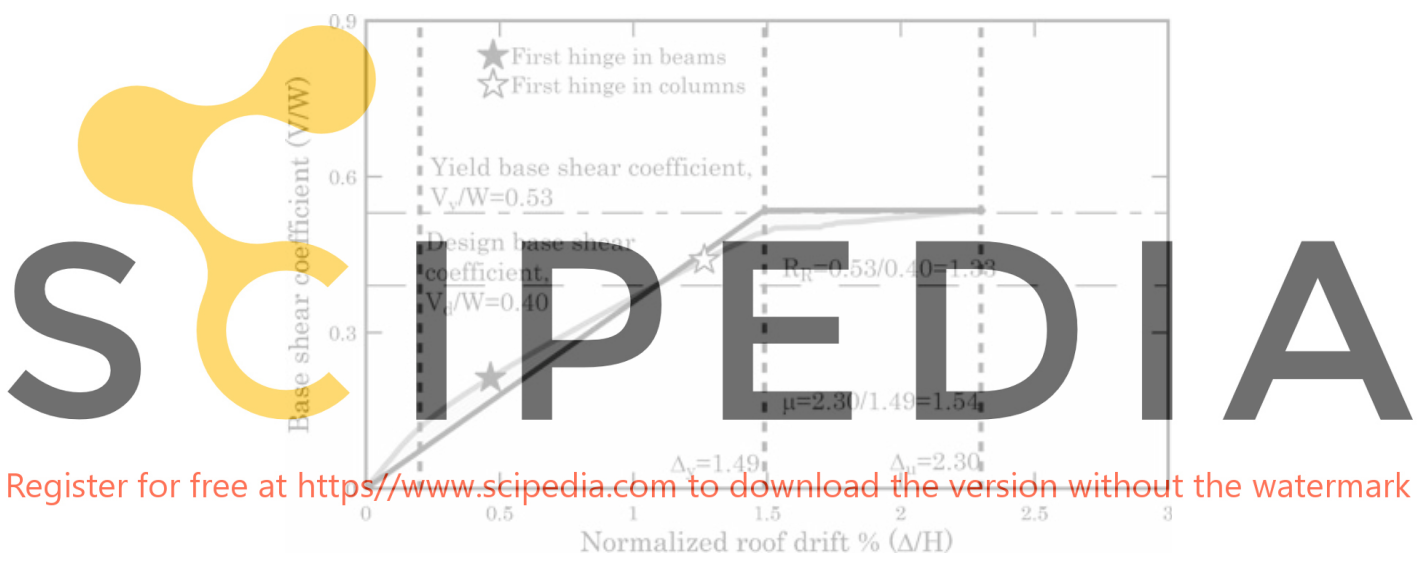

Fig. 6 Idealized capacity curve for the FBFB

closest to the slab-column node and to the middle of the span, where the greatest bending moments frequently appear.

In the Spanish seismic code NCSE-02, FBFB have a lower ductility values than those with deep beams. It is technically difficult to reinforce adequately flat beams in order to assure a ductile overall structural behavior. Figure 6 shows the global response of the FBFB up to the ultimate drift (i.e., the drift before total structural collapse) which, together with the yield drift, enables calculation of the displacement ductility.

Figure 5 indicates that the behavior of the FBFB remains elastic while the base shear coefficient is relatively low (i.e., less than 0.10). Nonetheless, it is not this value which is used to calculate the ductility of the building; rather, it is the yielding value obtained from the idealized bilinear curve which is used. The figure also shows the calculation of the ductility using the idealized bilinear capacity curve. As observed, the ductility obtained for the FBFB is 1.54 , a value which raises some concern given that the NCSE-02 earthquake-resistant code recommends behavior factor of 2 .

The response of the FBFB shows that the stability of the structure depends on the behavior of the beams. This is an important aspect to consider when deciding between a MRFB and a 


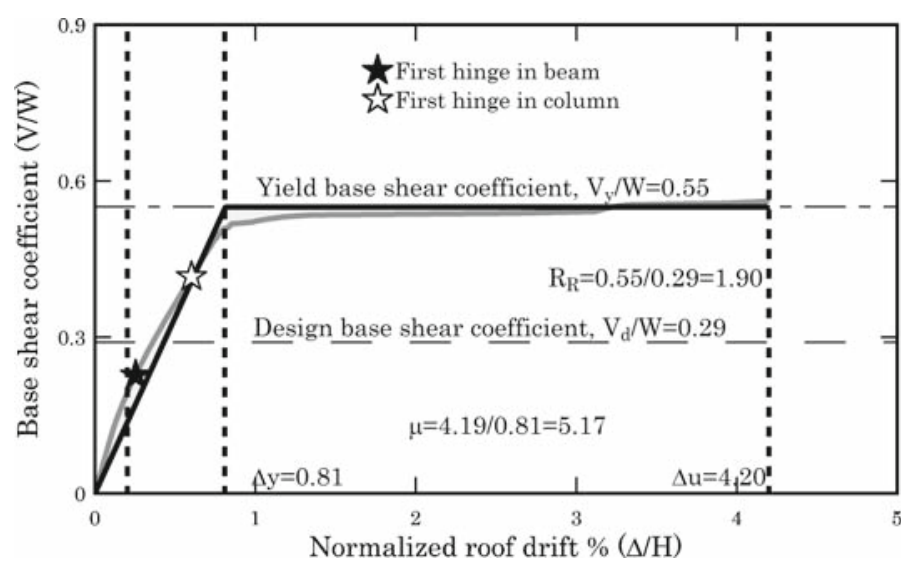

Fig. 7 Idealized capacity curve of the MRFB (EHE)

FBFB, given that the latter has lower ductility values than the values prescribed by the code and, consequently, lower response behavior factors $q$. However, the main problem with flat beams is the high flexibility and the implications this has with respect to the columns of the frames.
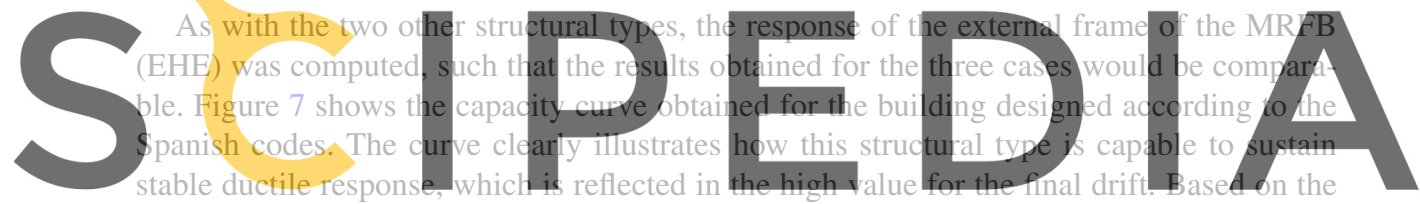

idealized bilinear curve in Fig. 7, a ductility factor of 5,17 is obtained-a higher value than

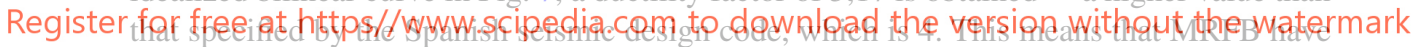

a ductile response to seismic forces, as well as an adequate overstrength.

Figure 8 show the capacity curve for the external frame of the MRFB (EC). The main difference between this building and the former is, by one hand, that the Spanish earthquakeresistant code limits the ductility factor for this class of buildings to 4 and, by the other hand, that the Spanish code requires less transversal and longitudinal than EC-2/EC-8 which enables greater dissipation capacity. The study shows that this building has a high displacement ductility value $(\mu=9.28)$ product of the adequate capacity of sustaining lateral forces without loss of stability.

Finally, the non-linear response of the studied MRFB is typical for low-rise reinforced concrete buildings, which generally undergo plastic hinges at the base of their ground floor columns.

\subsection{Non-linear dynamic analysis}

In order to evaluate the dynamic response of the buildings, the Incremental Dynamic Analysis procedure (IDA) was applied. This procedure (Vamvatsikos and Cornell 2002) consists of conducting time-history analyzes for seismic ground motions or for artificial accelerograms, which are scaled each time in order to induce increasing levels of inelasticity. A set of ten artificially synthesized accelerogram compatible with the NCSE-02 design spectrum were generated. Figure 9 show the design spectrum and 5\% damping response spectra computed 


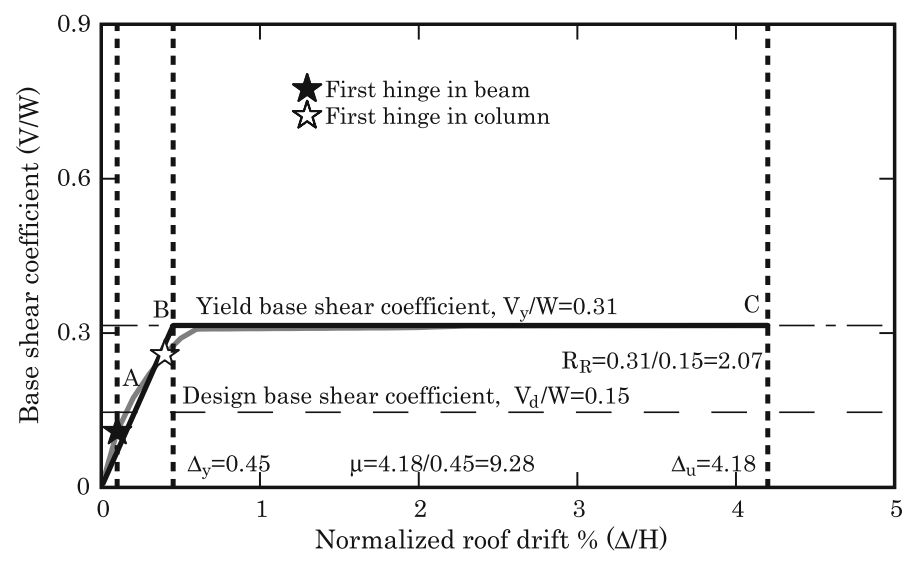

Fig. 8 Idealized capacity curve of the MRFB (EC)

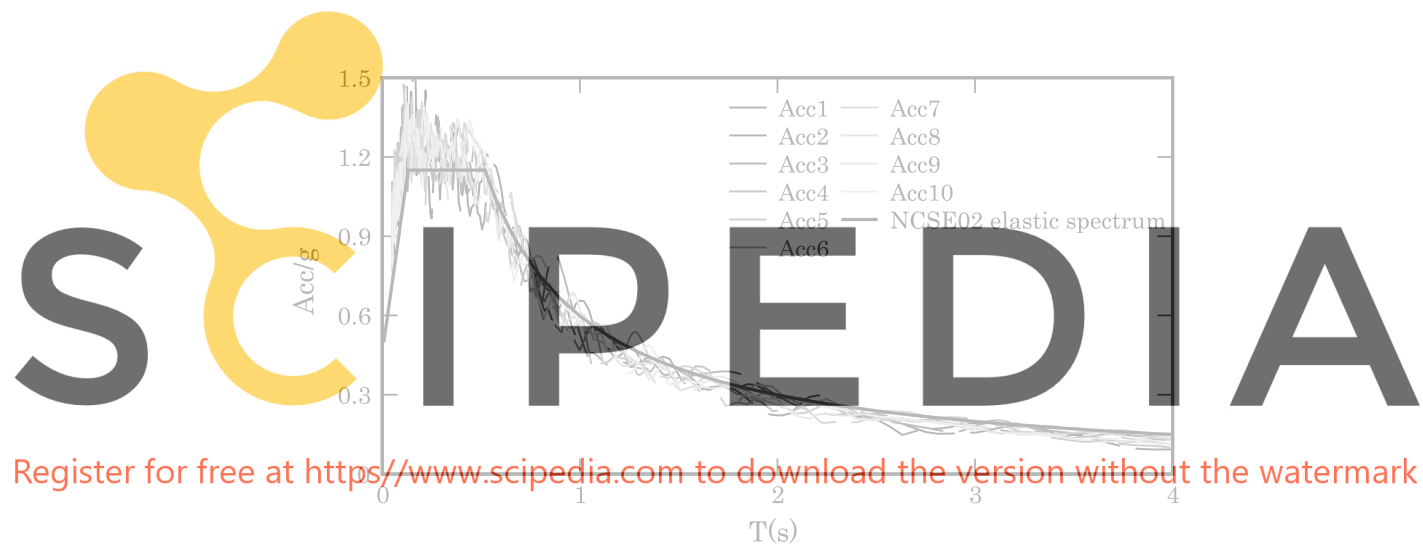

Fig. 9 NCSE-02 design spectrum and the response spectra used in dynamic analysis

from the set of synthetic accelerograms. A similar procedure was adopted for the dynamic analysis of the MRFB (EC) using the elastic design spectra for soil type B and the same peak acceleration to generate the set of ten synthetic accelerograms used in the analysis.

IDA curves are obtained plotting the ground motion intensity versus the demand parameters; in this study they are the spectral accelerations of the 5\% damped spectra and the roof drifts, respectively. The collapse state is reached when the capacity of the structure drops (Kunnath 2005). A usual criterion is to consider the slope of the curve less than the $20 \%$ of the elastic slope (Vamvatsikos and Cornell 2002; Han and Chopra 2006). Figure 10 show the IDA curves computed for the FBFB, WSB, MRFB (EHE), and MRFB (EC) structural models. Note that the collapse points of the FBFB correspond to a normalized roof drift between 1.83 and 2.54, in contrast with the collapse point obtained by means of pushover analysis, which is 2.29. In the case of the WSB, the collapse points obtained from the IDA curves are within a range of the normalized roof drift between 2.37 and 3.19, while a collapse point of 2.88 is obtained from the pushover analysis. 


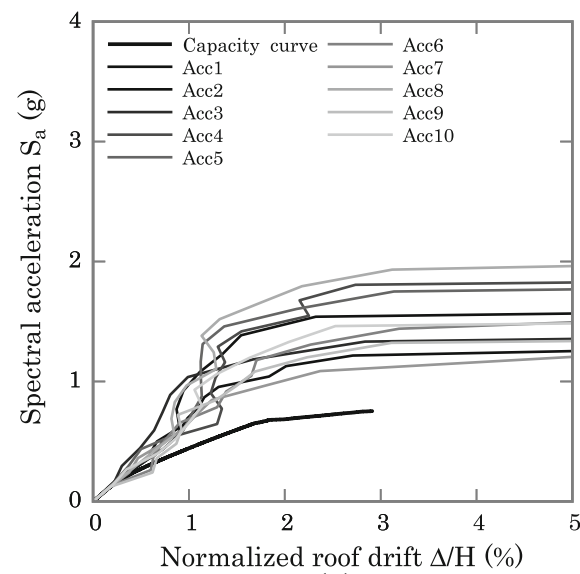

(a)

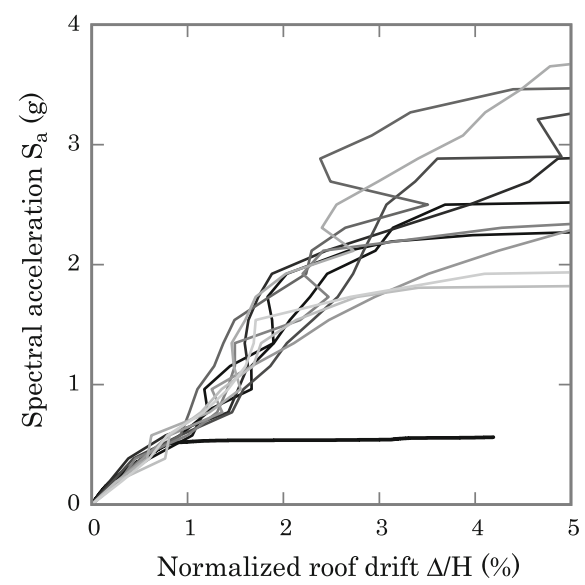

(c)

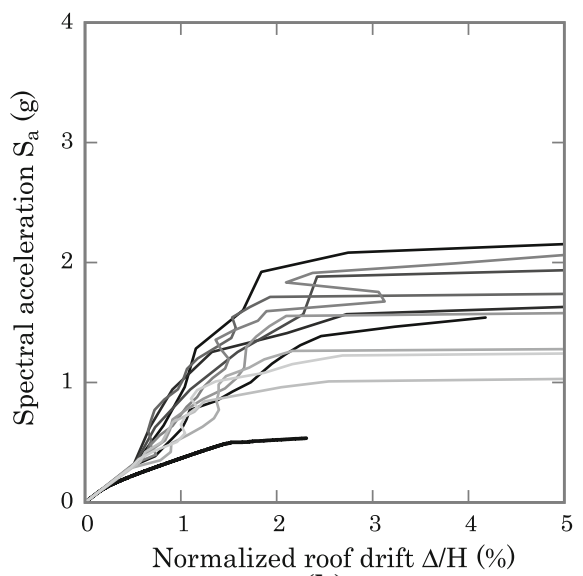

(b)

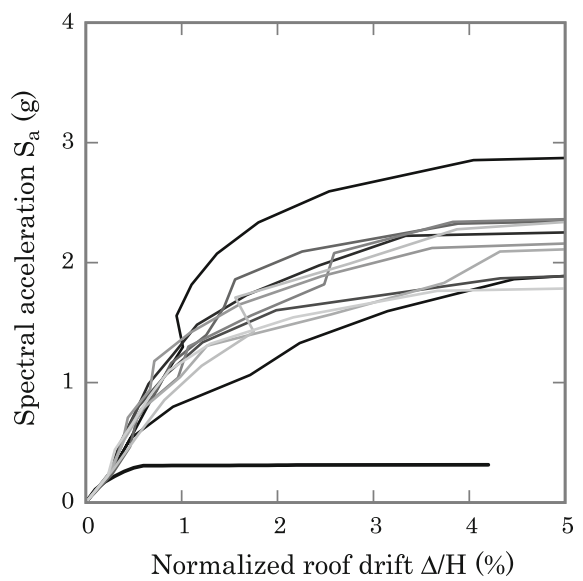

(d)

Fig. 10 IDA curves of the a WSB b FBFB $\mathbf{c}$ MRFB (EHE) and $\mathbf{d}$ MRFB (EC)

Table 2 Normalized roof displacement $(\%)$ at the collapse state of the structures

\begin{tabular}{lll}
\hline & Static analysis & Dynamic analysis (average) \\
\hline WSB & 2.88 & 2.72 \\
FBFB & 2.29 & 2.43 \\
MRFB (EHE) & 4.20 & 4.24 \\
MRFB (EC) & 4.18 & 3.93 \\
\hline
\end{tabular}

Table 2 summarizes the average values of the collapse points for all the studied cases, computed by means of the dynamic analysis.

Dynamic analysis is useful to assess the collapse points of the buildings, and to obtain the values of the behavior factors $q$. Mwafi and Elnashai (2002b) have proposed the following equation for the calculation of the behavior factor $q$ : 
Table 3 Behavior factors of the buildings

\begin{tabular}{lcll}
\hline & $q_{\text {equation }}($ Average) & $q_{\text {code }}$ & $q_{\text {equation }} / q_{\text {code }}$ \\
\hline WSB & 3.84 & 2.00 & 1.92 \\
FBFB & 3.88 & 2.00 & 1.94 \\
MRFB (EHE) & 8.95 & 4.00 & 2.24 \\
MRFB (EC) & 14.85 & 5.85 & 2.54 \\
\hline
\end{tabular}

$$
q=\frac{a_{\mathrm{g}(\text { collapse })}}{a_{\mathrm{g}(\text { design_yield })}}
$$

where $a_{\mathrm{g} \text { (collapse) }}$ and $a_{\mathrm{g} \text { (design_yield) }}$ are the collapse and the yield design peak ground acceleration, respectively. The former value is obtained from the IDA curves and the latter one is computed from the elastic analysis of the building. Average values of the calculated behavior factor $q$ of the studied buildings are show in Table 3; these values correspond to the dynamic response for the set of ten synthesized accelerograms, and are compared with behavior factors prescribed by the design codes.

The computed behavior factors show that the applied seismic design produces structures with satisfactory lateral capacity when they are subjected to strong ground motions, regardless of the structural typology. The relationship between the calculated and the prescribed behavior factors is close to two for the case of buildings with low ductility and greater than this value in the case of the MRFB.

\section{Possibilities of improving the seismic response of buildings with low ductility}

Figure 11 shows the capacity curves corresponding to the four studied cases. As it can be observed in the figure, each of the four buildings has the base shear coefficient greater than the design one, indicating that they satisfy this initial design objective. However, the overstrength varies dramatically among the different structures. It is interesting to compare the capacity curves of the MRFB, which have similar structural typology but are designed with different codes and, thus, their behavior factors differ. Both of these buildings exhibit a ductile response; their ductility is several times higher than either that of the FBFB, or that of the WSB. In summary, among the typologies studied here, only the MRFB guarantees a ductile response while providing satisfactory overstrength.

The results of the non-linear analysis of the response of buildings with low ductility raise the question: Can these responses be improved at the design stage, to reach the ductility values prescribed in the code NCSE-02 while maintaining the same structural type? This section discusses this possibility for buildings with either WSB or FBFB, based on the pushover analysis performed using finite element method. The improved responses are finally compared with the responses obtained for MRFB.

Table 4 summarizes how each of the three structural types is considered in the seismic design codes NCSE-02 and EC-8. As seen in this table, the NCSE-02 code does not recommend FBFB for high ductility, whereas EC-8 allows them for medium ductility, albeit with certain restrictions on the beam width.

With the aim of studying the influence of the steel type on the non-linear response of WSB, steel with different mechanical characteristics was considered. The buildings were calculated by using reinforcement with either weldable ductile steel (WD), whose characteristics make it recommendable for the design of structures according to the EHE and EC-8 specifications, 


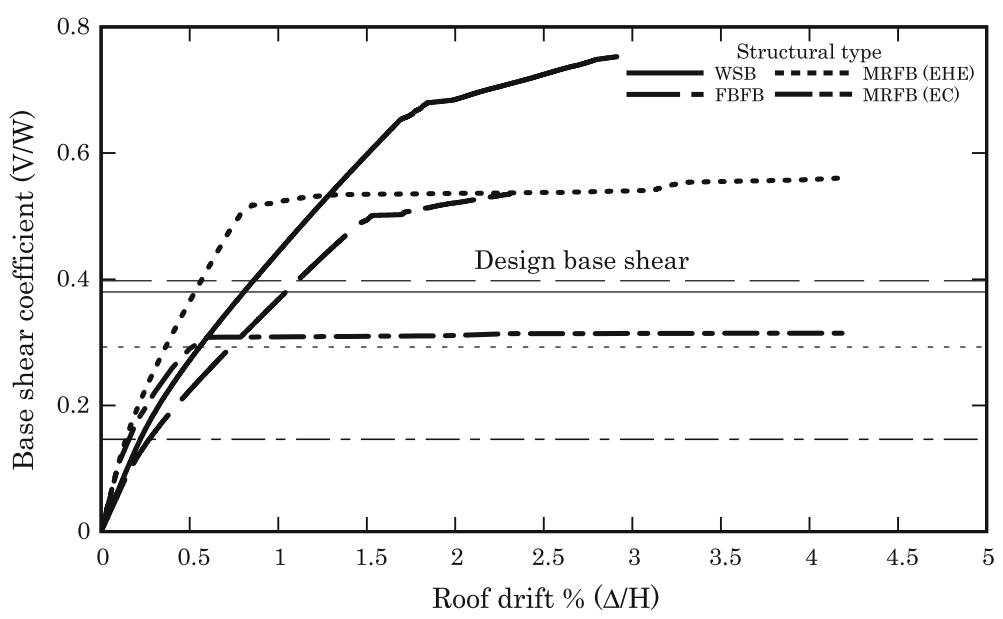

Fig. 11 Comparison of the non-linear response of the four building types studied

Table 4 Comparison of the structural types that can be used for buildings in seismic zones

${ }^{\text {a }}$ EC-8 limits beam's width for intermediate ductility to: where, $\mathrm{bw} \leq \min \{\mathrm{bc}+\mathrm{hw} ; 2 \mathrm{bc}\}$;

$\mathrm{bw}=$ width of the beam;

$h w=$ heigth of the beam;

$\mathrm{bc}=$ largest cross sectional dimension of the column normal to the longitudinal axis of the beam

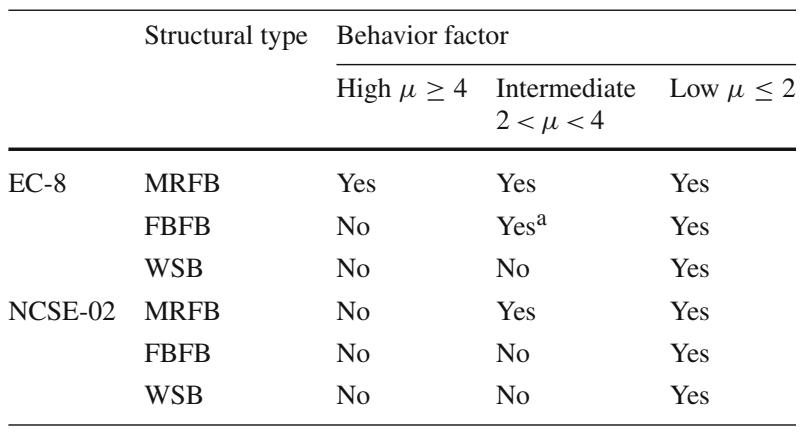

Table 5 Characteristics of the steel recommended for the design of ductile reinforced concrete buildings

\begin{tabular}{llllll}
\hline Steel type & \multicolumn{2}{l}{ Eurocode 8} & & \multicolumn{2}{l}{ EHE } \\
\cline { 2 - 3 } & B & C & & B400WD & B500WD \\
\hline Yield stress Fy $\left(\mathrm{N} / \mathrm{mm}^{2}\right)$ & $400-600$ & $400-600$ & & 400 & 500 \\
Ultimate stress Fy $\left(\mathrm{N} / \mathrm{mm}^{2}\right)$ & - & - & 480 & 575 \\
Ratio Fs/Fy & $\geq 1.08$ & $\geq 1.15$ and $\leq 1.35$ & $\geq 1.20$ and $\leq 1.35$ & $\geq 1.15$ and $\leq 1.35$ \\
Maximum strain $\varepsilon \max (\%)$ & $\geq 5.00$ & $\geq 7.50$ & & $\geq 9.00$ & $\geq 8.00$ \\
Ultimate strain $\varepsilon \mathrm{u}(\%)$ & - & - & $\geq 20.00$ & $\geq 16.00$ \\
\hline
\end{tabular}

or weldable steel (W) (see Table 5). In both cases, the yield stress B 400 and B 500 steel were considered.

The results of the pushover analyzes are shown in Fig. 12, which reveals that frames reinforced with ductile steel have only a slightly more ductile response than do those reinforced with non-ductile steel. Hence, the global response of the building is influenced to a much greater extent by the general configuration and structural typology chosen than by the characteristics of the reinforcement steel. 


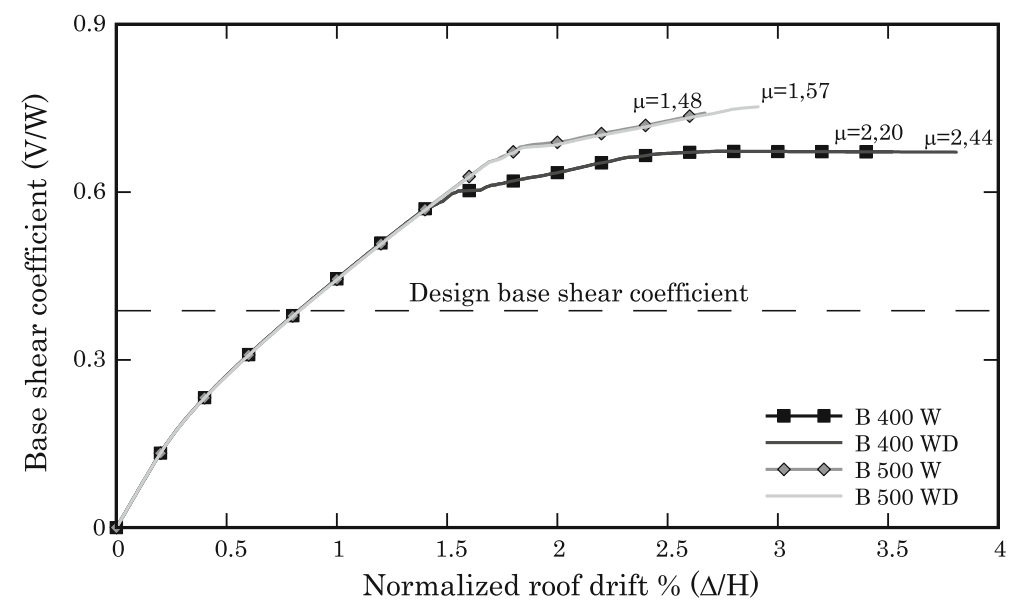

Fig. 12 Capacity curves of the WSB reinforced with steel of different mechanical characteristics

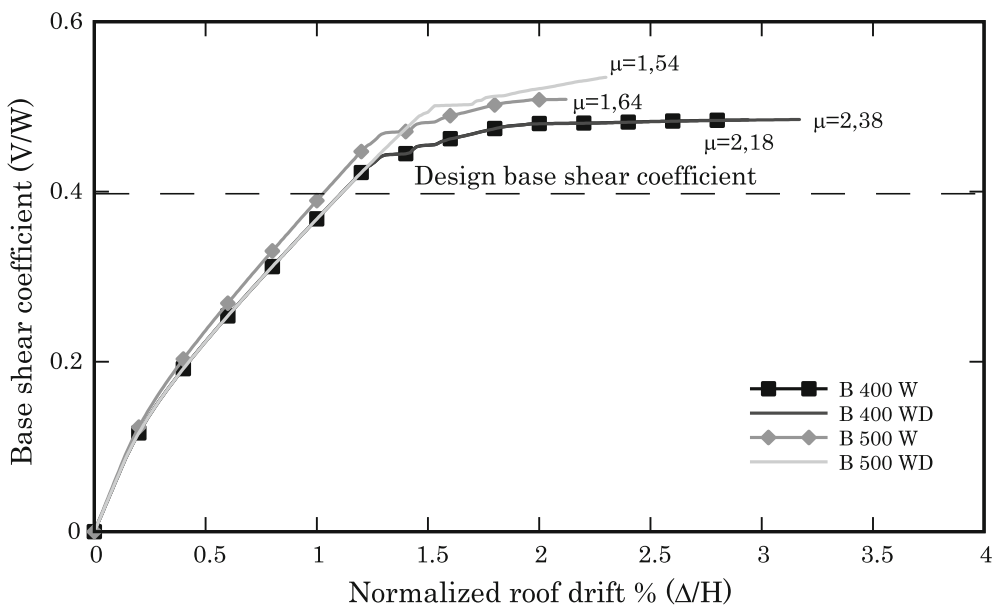

Fig. 13 Capacity curve of the FBFB reinforced with steel of different mechanical characteristics

The behavior of FBFB that are reinforced with ductile (WD) or non-ductile (W) steels and with yield stress values of 400 or 500 is also studied. Just as in the case of the WSB, the ductile capacity of this type of building was found to be far more influenced by the structural type than by the type of steel (see Fig. 13).

Finally, Fig. 14 shows the same results obtained for the MRFB (EHE) reinforced with different types of steel. Observe that, in this case, increasing the ductility of the steel leads to a major increase in structural ductility.

\section{Fragility curves and damage probability matrices}

In order to evaluate the non-linear behavior of the buildings, the performance points were calculated. These points, corresponding to the maximum drift induced by the seismic demand 


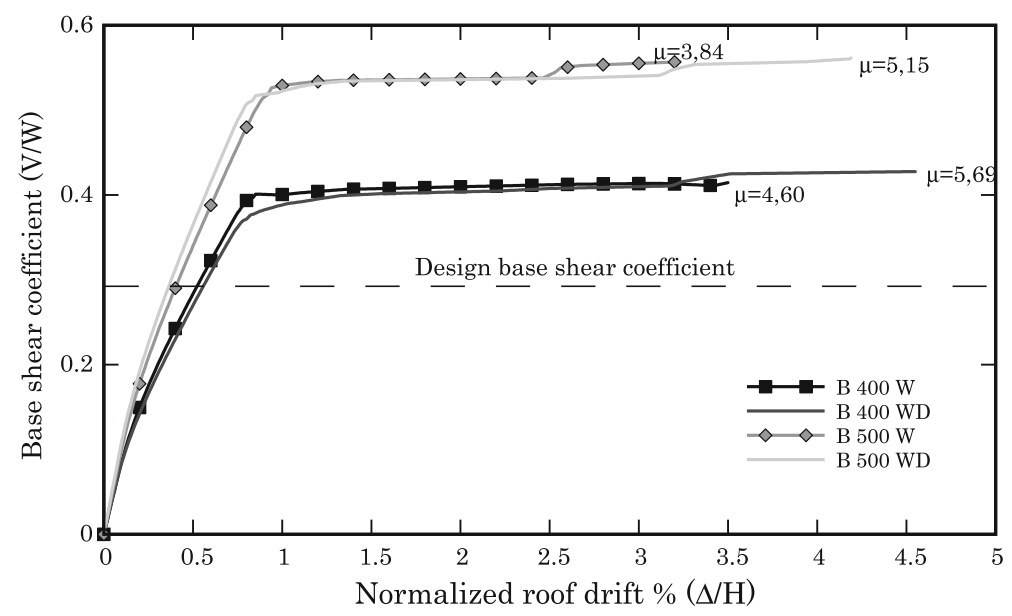

Fig. 14 Capacity curve of the MRFB (EHE) reinforced with steel of different mechanical characteristics

in an equivalent single degree of freedom model, are determined by means of the N2 procedure (Fajfar 2000). N2 procedure requires transforming the capacity curve into the capacity spectrum expressed in spectral displacements $S_{\mathrm{d}}$-spectral acceleration $S_{\mathrm{a}}$ coordinates. The former are obtained by applying the equation

$$
S_{\mathrm{d}}=\frac{\delta_{\mathrm{c}}}{\mathrm{MPF}}
$$

where $\delta_{\mathrm{c}}$ are the roof displacements and MPF is the modal participation factor computed from the response of the first vibration mode

$$
\mathrm{MPF}=\frac{\sum_{i=1}^{n} m_{i} \phi_{1, i}}{\sum_{i=1}^{n} m_{i} \phi_{1, i}^{2}}
$$

where $m_{i}$ is the mass at $i$ th level and $\phi_{1, i}$ is the first modal shape.

The spectral accelerations $S_{\mathrm{a}}$ are given by the equation

$$
S_{a}=\frac{V / W}{\alpha}
$$

where $V$ is the base shear, $W$ is the seismic weight and $\alpha$ is a coefficient given by

$$
\alpha=\frac{\left(\sum_{i=1}^{n} m_{i} \phi_{1, i}\right)^{2}}{\sum_{i=1}^{n} m_{i} \phi_{1, i}^{2}}
$$

Figures 15, 16, and 17 show the capacity spectra for the WSB, FBFB, and MRFB (EHE) crossed with the corresponding demand spectrum and with the elastic response spectrum. The idealized bilinear form of the capacity spectra is also given.

Values of the spectral displacements corresponding to the performance point are shown in Table 6. An important feature in the non linear response of the buildings is the ratio between the performance point displacement and the ultimate displacement. This ratio indicates whether the behavior of a structure is ductile or fragile. The latter occurs when the ratio tends to one, which is the case of the WSB and the FBFB. It can be observed in Table 6 that MRFB have significantly lower values. 


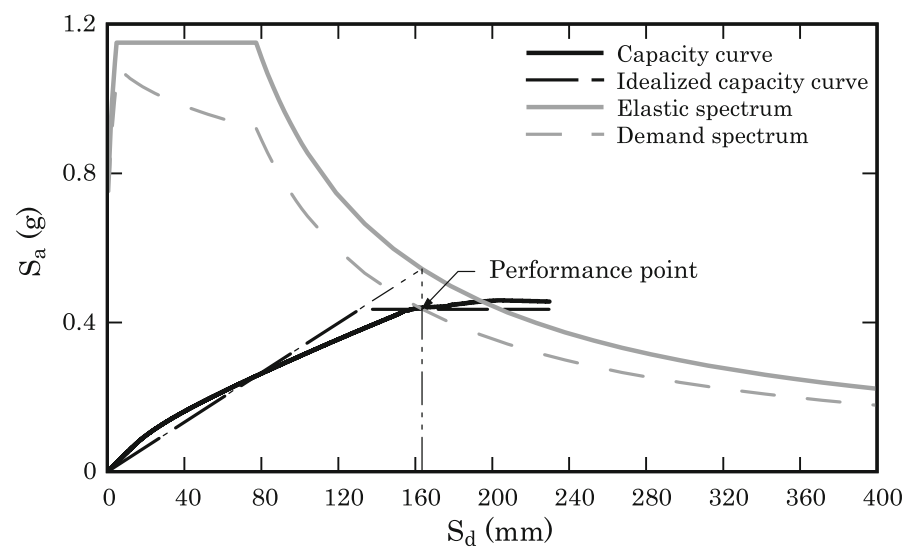

Fig. 15 Capacity and demand spectra allowing the determination of the performance point of the WSB

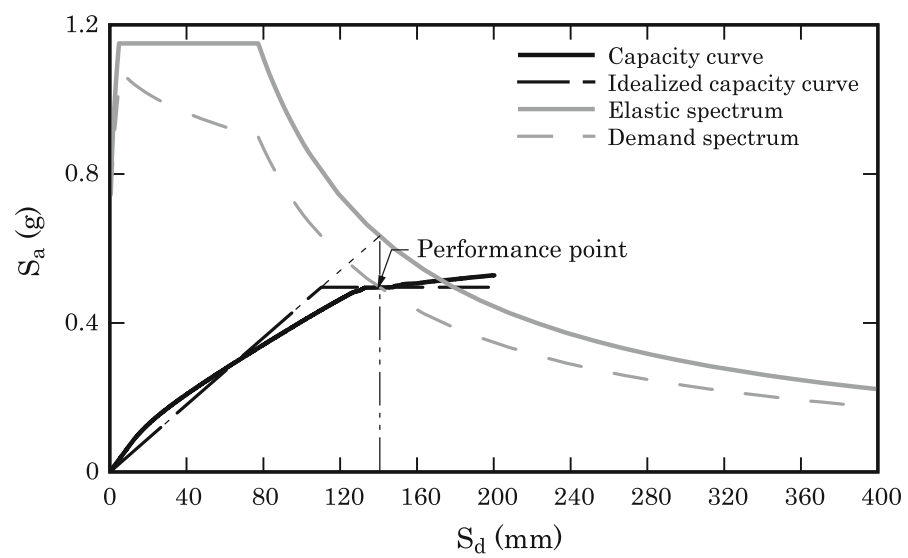

Fig. 16 Capacity and demand spectra allowing the determination of the performance point of the FBFB

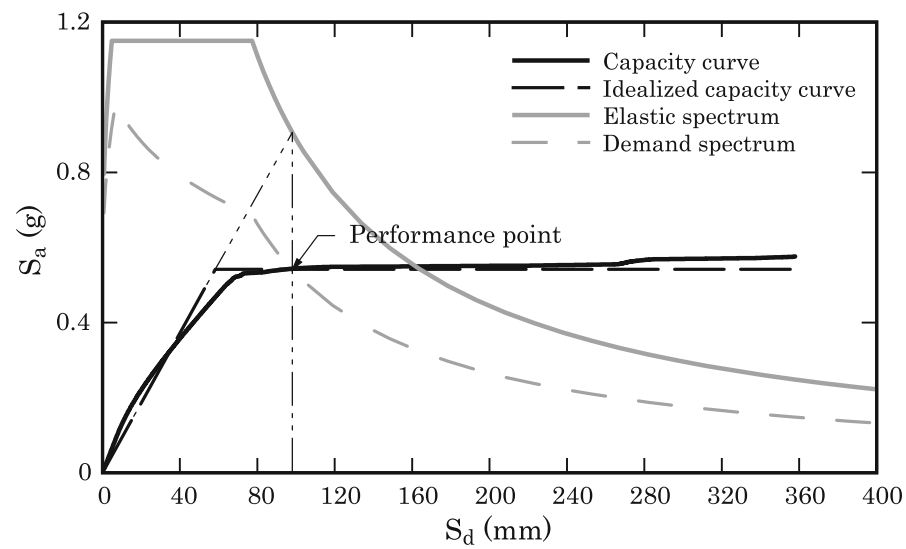

Fig. 17 Capacity and demand spectra allowing the determination of the performance point of the MRFB (EHE) 
Table 6 Roof drift of performance points for studied buildings

\begin{tabular}{|c|c|c|c|c|c|}
\hline \multirow[t]{2}{*}{ Structural type } & \multicolumn{3}{|c|}{ Normalized roof drift $(\%)$} & \multicolumn{2}{|l|}{ Ratio } \\
\hline & $\begin{array}{l}\text { Perfor- } \\
\text { mance } \\
\text { point }(\%)\end{array}$ & $\begin{array}{l}\text { Static anal- } \\
\text { ysis }\end{array}$ & $\begin{array}{l}\text { Dynamic } \\
\text { analysis } \\
\text { (average) }\end{array}$ & $\begin{array}{l}\text { Static anal- } \\
\text { ysis }\end{array}$ & $\begin{array}{l}\text { Dynamic } \\
\text { analysis } \\
\text { (average) }\end{array}$ \\
\hline WSB & 2.11 & 2.88 & 2.72 & 0.73 & 0.78 \\
\hline FBFB & 1.62 & 2.29 & 2.33 & 0.71 & 0.70 \\
\hline MRFB & 1.14 & 4.18 & 4.24 & 0.27 & 0.27 \\
\hline
\end{tabular}

Table 7 Mean values and standard deviation of the normalized roof drift for limit states

\begin{tabular}{|c|c|c|c|c|c|c|}
\hline \multirow[t]{2}{*}{ Limit State } & \multicolumn{2}{|l|}{ WSB } & \multicolumn{2}{|l|}{ FBFB } & \multicolumn{2}{|c|}{ MRFB (EHE) } \\
\hline & Mean & SD & Mean & SD & Mean & SD \\
\hline Slight damage & 0.22 & 0.03 & 0.15 & 0.02 & 0.16 & 0.07 \\
\hline Moderate damage & 0.67 & 0.04 & 0.68 & 0.05 & 0.93 & 0.12 \\
\hline Severe damage & 1.67 & 0.11 & 1.66 & 0.10 & 2.06 & 0.11 \\
\hline Collapse & 2.88 & 0.16 & 2.43 & 0.14 & 4.24 & 0.17 \\
\hline
\end{tabular}

Damage thresholds are determined by using the VISION 2000 (SEAOC 1995) procedure which expresses the thresholds in function of interstory drifts. Damage states thresholds are determined from both interstory drift curve and capacity curve. For the slight damage state, the roof drift corresponding to the first plastic hinge is considered. The moderate damage state corresponds to the roof drift for which an interstorey drift of $1 \%$ is reached in all of the storeys of the structure. The severe damage state is identified by a roof drift producing a 2,5\% of interstorey drift at each of the levels. Finally, the total damage state (collapse) corresponds to the ultimate roof displacement obtained from the capacity curve (Vielma 2008). Mean values and standard deviation were computed from the non linear response of buildings with the same geometry and structural type, varying the number of spans from 3 to 6 in $x$ direction. These values are show in Table 7.

Fragility curves are obtained by using the spectral displacements determined for the damage thresholds and considering a lognormal probability density function for the spectral displacements which define the damage states (Pinto et al. 2006)

$$
F\left(S_{\mathrm{d}}\right)=\frac{1}{\beta_{\mathrm{ds}} S_{\mathrm{d}} \sqrt{2 \pi}} \exp \left[-\frac{1}{2}\left(\frac{1}{\beta_{\mathrm{ds}}} \ln \frac{S_{\mathrm{d}}}{\overline{S_{\mathrm{d}, \mathrm{ds}}}}\right)^{2}\right]
$$

where $\bar{S}_{\mathrm{d} \text {,ds }}$ is the mean value of the spectral displacement for which the building reaches the damage state threshold $d_{\mathrm{s}}$ and $\beta_{\mathrm{ds}}$ is the standard deviation of the natural logarithm of the spectral displacement for the damage state $d_{\mathrm{s}}$. The conditional probability $P\left(S_{\mathrm{d}}\right)$ of reaching or exceeding a particular damage state $d_{\mathrm{s}}$, given the spectral displacement $S_{\mathrm{d}}$, is defined as

$$
P\left(S_{\mathrm{d}}\right)=\int_{0}^{S_{\mathrm{d}}} F\left(S_{\mathrm{d}}\right) d\left(S_{\mathrm{d}}\right)
$$




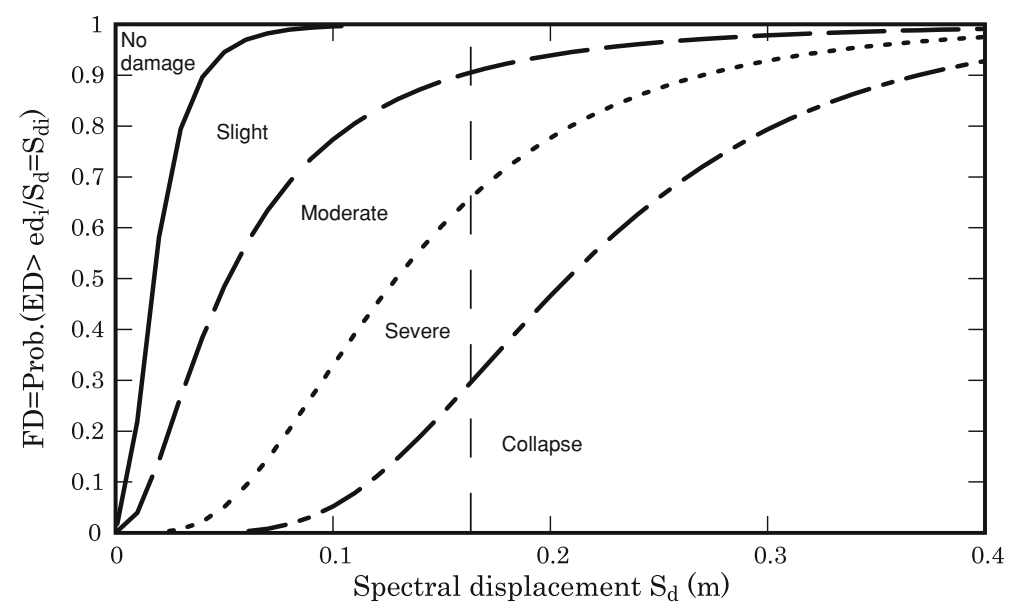

Fig. 18 Fragility curves of the WSB

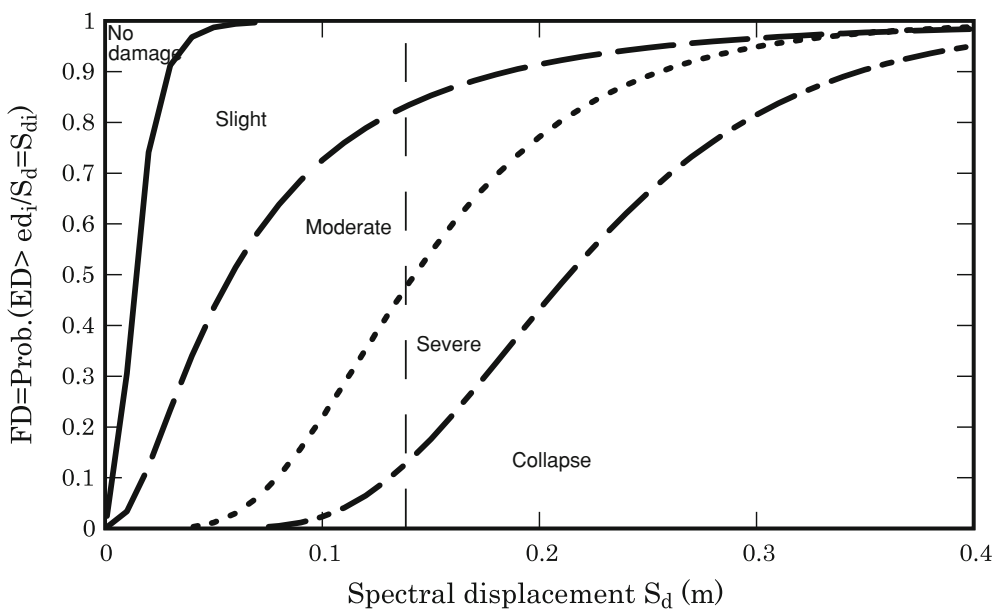

Fig. 19 Fragility curves of the FBFB

Figures 18, 19, and 20 show the fragility curves calculated for the three building typologies considered in the analysis.

The damage probability matrices are calculated by entering the spectral displacement corresponding to the performance point into the fragility curves. The obtained values represent the exceedance probabilities of a damage state and are given in Table 8 for the three building typologies considered in the analysis. This Table shows that for the considered demand, there is a high probability that the low ductility buildings exceed the severe damage state and the collapse state. This severe damage state exceedance probability is of $36.3 \%$ for the WSB and of $37.7 \%$, for that FBFB. The collapse probabilities are $29.6 \%$ for the WSB and $12.7 \%$ for the FBFB. It can be also seen that for MRFB (EHE) the exceeding probabilities for these damage states are lower. 


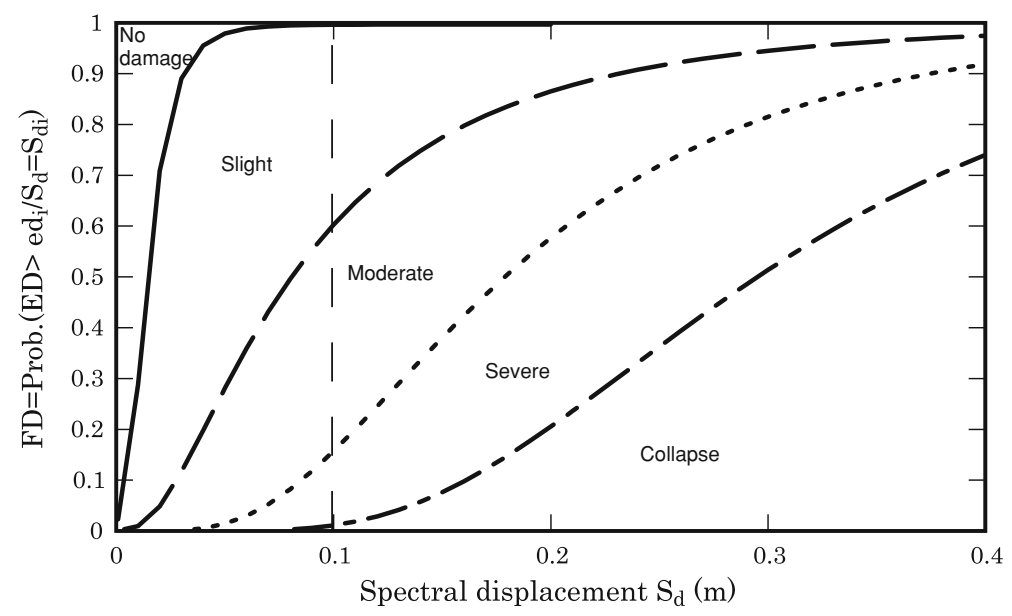

Fig. 20 Fragility curves of the MRFB (EHE)

Table 8 Damage probability matrices (in \%) for the three building typologies

In bold: maximum damage probability

\begin{tabular}{lrrr}
\hline & \multicolumn{2}{l}{ Building } & \\
\cline { 2 - 4 } & WSB & FBFB & MRFB (EHE) \\
\hline Non damage & 0.03 & 0.08 & 0.39 \\
Slight & 9.43 & 16.79 & 39.67 \\
Moderate & 24.66 & 32.71 & $\mathbf{4 4 . 4 8}$ \\
Severe & $\mathbf{3 6 . 2 9}$ & $\mathbf{3 7 . 6 8}$ & 14.37 \\
Collapse & 29.58 & 12.74 & 1.09 \\
\hline
\end{tabular}

\section{Conclusions}

In order to evaluate the response of the buildings, non-linear static and dynamic analyzes were used. The ultimate roof drift of the structure determined from static analysis was validated with the results obtained from the incremental dynamic analysis.

The yield drifts of the frames are obtained by using the idealized bilinear capacity curves and the procedure proposed by Park (1988). Despite of the absence of a unified criterion within the research community, this bilinear capacity curve proved to be adequate for equilibrating the energy of the non-linear response derived from pushover analysis with the idealized non-linear response. The bilinear shaped capacity curve is used in order to calculate the displacement ductility. WSB and FBFB show values lower than those prescribed by the NCSE-02 code.

Behavior factors $q$ were calibrated by applying incremental dynamic analyzes with a set of ten synthetic accelerograms. All buildings had values greater than those prescribed by the codes, even the WSB and FBFB. The ratios between MRFB behavior factors and the code values are grater than two. Among the non-linear responses of the cases studied, only the MRFB exhibits ductility and overstrength which guarantee a stable behavior, including for ductility values higher than the design one. During earthquakes, buildings with low ductility showed high overstrength, provided that their response remains within the elastic range. It is also confirmed the premise that greater resistance leads to less ductility: structures 
modelled with B 500 WD have higher overstrength and lower ductility than do those built with B 400 WD.

The global behavior of FBFB and WSB is influenced in great part by the structural type. If these buildings are reinforced with WD steel, they exhibit slightly higher ductility than if reinforced with W steel. However, for the case of MRFB, the use of WD steel instead of W steel provides a substantial increase in the ductility.

Ductile response of the FBFB cannot be greatly improved via confinement of its elements; to improve their response, adequate configuration and dimensioning of the cross sections are also required. Good confinement alone is only advantageous for MRFB.

The ratio of the performance point displacement to the ultimate displacement is a measure of the ductility of the behavior of a structure. In this study, values computed by means of static and dynamic analyzes of the WSB and FBFB are greater than 0.7, showing that these buildings have a fragile response. By contrast, MRFB have lower values (0.24).

Among the studied buildings, the FBFB and the WSB show a greater probability of reaching states of severe damage compared with the MRFB, when they are subjected to seismic demand typified by the design spectrum.

\section{References}

ACI Comitee 318 (2005) Building code requirements for structural concrete ACI 318-05. Farmington Hills, Michigan

Barbat AH, Oller S, Mata P, Vielma JC (2008) Computational simulation of the seismic response of buildings with energy dissipating devices. In: Papadrakakis M, Charmpis D, Lagaros N, Tsompanakis Y (eds) Computational structural dynamics and earthquake engineering, vol 2. Taylor \& Francis Ltd, London, pp 255-274

Car E, Oller S, Oñate E (2000) An anisotropic elasto plastic constitutive model for large strain analysis of fiber reinforced composite materials. Comput Methods Appl Mech Eng 185(2-4):245-277. doi:10.1016/ S0045-7825(99)00262-5

Car E, Oller S, Oñate E (2001) A large strain plasticity for anisotropic materials: composite material application. Int J Plast 17(11):1437-1463. doi:10.1016/S0749-6419(00)00098-X

CEN (2001) European Committee for Standardization, Eurocode 2: Design of concrete structures, BS EN 1992, Brussels

CEN (2004) European Committee for Standardization, Eurocode 8: Design of structures for earthquake resistance, Part 1: General rules, seismic actions and rules for buildings, EN 2004-1-1, Brussels

EHE (1998) Comisión permanente del hormigón estructural, Instrucción de hormigón estructural, Madrid

Erberik A, Elnashai A (2006) Loss estimation analysis of flat-slab structures. J Struct Eng 7(1):26-37

Fajfar P (2000) A nonlinear analysis method for perfomance based seismic design. Earthq Spectra 16:573-591. doi:10.1193/1.1586128

Fragiacomo M, Amadio C, Rajgelj S (2006) Evaluation of the structural response Ander seismic actions using non-linear static methods. Earthq Eng Struct Dynam 35:1511-1531. doi:10.1002/eqe.597

Han SW, Chopra A (2006) Approximate incremental dynamic analysis using the modal pushover analysis procedure. Earthq Eng Struct Dynam 35(3):1853-1873. doi:10.1002/eqe.605

ICBO (1997) International Council of Building Officials. Uniform Building Code (UBC), Whittier

ICC (2003) International Code Council. International Building Code (IBC), Falls Church

Kunnath S (2005) Performance-based seismic design and evaluation of buildings structures. In: Chen W, Lui E (eds) Earthquake engineering for structural design. CRC Press, Boca Raton

Mander JB, Priestley MJN, Park R (1988) Observed stress-strain behavior of confined concrete. J Struct Eng 114(8):1827-1849. doi:10.1061/(ASCE)0733-9445(1988)114:8(1827)

Mata P, Oller S, Barbat AH (2007) Static analysis of beam structures under nonlinear geometric and constitutive behavior. Comput Methods Appl Mech Eng 196:4458-4478. doi:10.1016/j.cma.2007.05.005

Mata P, Oller S, Barbat AH (2008a) Dynamic analysis of beam structures under nonlinear geometric and constitutive nonlinearity. Comput Methods Appl Mech Eng 197:857-878

Mata P, Oller S, Barbat AH, Boroschek R (2008b) Constitutive and geometric nonlinear models for the seismic analysis of RC structures with energy dissipators. Arch Comput Methods Eng 15:489-539. doi:10.1007/ s11831-008-9024-z 
Mwafi A, Elnashai A (2002a) Overstrength and force reduction factors of multistorey reinforced-concrete buildings. Struct Des Tall Build 11:329-351. doi:10.1002/tal.204

Mwafi AM, Elnashai A (2002b) Calibration of force reduction factors of RC buildings. J Earthq Eng 6(2): 239-273. doi:10.1142/S1363246902000723

NCSE-02 (2002) Norma de construcción sismorresistente, BOE $\mathrm{N}^{\circ}$ 244, Madrid. Available via http://www. proteccioncivil.es/es/Galerias/Descargas/DGPCE/legisla/NCSR-02.pdf. Accessed 20 May 2009

Park R (1988) State-of-the-art report: ductility evaluation from laboratory and analytical testing. In: Proceedings of 9th WCEE, IAEE, vol VIII. Tokyo-Kyoto, Japan, pp 605-616

Pinto PE, Giannini R, Franchin P (2006) Seismic reliability analysis of structures. IUSS Press, Pavia

PLCd (1991-2009) Non-linear thermo mechanic finite element code oriented to PhD student education, code developed at CIMNE

Priestley MJN, Calvi GM, Kowalsky MJ (2007) Displacement-based seismic design of structures. IUSS Press, Pavia

SEAOC (1995) Vision 2000. Report on performance based seismic engineering of buildings vol I. Structural Engineers Association of California, Sacramento

Simo JC (1985) A finite strain beam formulation. The three-dimensional dynamic problem. Part I. Comput Methods Appl Mech Eng 49:55-70

Vamvatsikos D, Cornell CA (2002) Incremental dynamic analysis. Earthq Eng Struct Dynam 31(3):491-514

Vielma JC (2008) Caracterización de la respuesta sísmica de edificios de hormigón armado mediante la respuesta no lineal. $\mathrm{PhD}$ Thesis, Universitat Politecnica de Catalunya, Spain

Vielma JC, Barbat AH, Oller S (2006) Comparación entre los factores de reducción de respuesta de la norma NCSE-02 y del Eurocódigo 8. Hormigón y acero 246:79-95

Vielma JC, Barbat AH, Oller S (2009) Seismic preformance of Waffled-Slab floor buildings. Proc P I Civil Eng-Str (in press) 